\title{
VANZOLINI, Marina. A flecha do ciúme: o parentesco e seu avesso segundo os Aweti do Alto Xingu. São Paulo: Terceiro Nome/FAPESP, 2015, 373p.

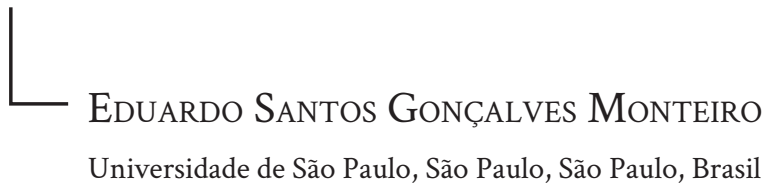

DOI 10.11606/issn.2316-9133.v25i25p475-481

Apesar de remeter a obras antropológicas clássicas, a feitiçaria constitui um campo de estudos relativamente pouco explorado pela etnologia indígena de povos amazônicos (cf. WHITEHEAD; WRIGHT, 2004). Contudo, o desenvolvimento recente de trabalhos etnográficos e sínteses etnológicas sobre o tema vem modificando a situação, para qual A flecha do ciúme certamente contribui de forma valiosa e original. O livro consiste numa versão revista e enxuta da tese de doutorado defendida pela autora no Programa de Pós-Graduação do $\mathrm{Mu}$ seu Nacional/UFRJ em 2010, resultado de trabalho de campo realizado entre os Aweti, grupo indígena do Alto Xingu e falante de língua tupi. De partida, é notável a qualidade da obra, seja por sua riqueza descritiva, pela fluidez com que articula descrição etnográfica e problemas centrais da teoria etnológica - estabelecendo profícuo diálogo entre os estudos xinguanos e os de outras regiões amazônicas -, ou pelas potências de seu "método do avesso" que, como aponta Renato Sztutman em seu belo prefácio, evidencia seu principal problema de pesquisa e, talvez, sua maior contribuição: a elucidação da relação necessária entre o parentesco e seu avesso, a feitiçaria e a fofoca, vetores opostos mas indissociáveis da produção da socialidade no Alto Xingu. Por meio de A flecha do ciúme, é possível habitar uma perspectiva menos evidenciada por quadros etnológicos construídos sobre esse sistema regional, nos quais certos traços hierárquicos e "pacifistas" acabam se sobressaindo aos demais.

A "Introdução" apresenta elementos que situam a obra, orientam a leitura e, sobretudo, lançam o problema etnográfico que dá ensejo à pesquisa. Nesse sentido, o livro pode ser entendido, indica a autora, como uma "tentativa de pensar o descompasso entre o lugar de onde se espera vir a feitiçaria e o lugar de onde ela geralmente vem" (p. 22): se é comum dizer que o feiticeiro provém de lugares distantes, ele, contudo, é gente próxima na maioria dos casos, é parente. Feitiçaria e parentesco vão se mostrando ambos como formas de influência produzidas através da manipulação e circulação de fluidos corporais e bens pessoais. O impulso etnográfico do trabalho é, portanto, a descrição, a partir do ponto de 
vista aweti, dos mecanismos de produção de uma diferença imanente à construção das relações de maior proximidade social.

A "influência” da etnografia de Roy Wagner entre os Daribi (1967) mostra-se fundamental para a obra, na medida em que permite reconsiderar o parentesco e a consanguinidade em chave complementar àquela privilegiada por certa etnologia americanista recente que enfatiza a precedência da afinidade sobre a consanguinidade e certos temas correlatos, como a guerra, a caça e o xamanismo. Assim, Vanzolini chama atenção para o papel do "dom como operador de corte" (p. 24) em fluxos de relações, para seu caráter diferenciante, indissociável da conexão que promove. O contraste entre essas relações de troca e as de compartilhamento generalizado, características da construção da consanguinidade, possui grande rendimento ao longo da reflexão de Vanzolini sobre o parentesco aweti e suas relações com os vizinhos xinguanos.

Ao mesmo tempo, uma série de afastamentos teóricos realizados no trabalho são aqui evidenciados: por um lado, busca-se relativizar "a imagem de um Xingu pré-estatal” (p. 32) hierarquizado e com crescente centralização de poder, projetado pelos trabalhos de etnologia e arqueologia de Michael Heckenberger, ${ }^{1}$ evidenciando forças centrífugas inerentes ao universo etnográfico em questão; por outro, um debate crítico é estabelecido com trabalhos que remetem as causas da feitiçaria a elementos externos à lógica xinguana, como a degeneração cultural do sistema ou a pressão externa causadas pelo avanço do contato. Trata-se, portanto, de buscar "descrever o que os Aweti dizem sobre por que se faz feitiço, e por que existe o feitiço no mundo" (p. 39) e, ao fazê-lo, evidenciar a centralidade da questão na vida xinguana. Nas palavras da autora:

Meu interesse nesta etnografia é entender os modos de identificação e diferenciação que levam os Aweti a se verem como parentes de uns e não de outros, parentes em determinadas circunstâncias e não outras, distintos pela língua ou pelo que é dito - mecanismos através dos quais veremos aparecer as diferenças "étnicas" entre os grupos xinguanos, mas também outras. Melhor dizendo, é dessas outras diferenças que me ocuparei ao longo deste trabalho. (p. 55)

No primeiro capítulo, "Mo'at e'ym tupiat itatza: os feiticeiros não são gente", Vanzolini busca elucidar uma teoria aweti da doença e refinar a definição de certas categorias fundamentais que são mobilizadas ao se lidar com o adoecimento, a cura xamânica e o diagnóstico da identidade do feiticeiro, entre elas as de "alma" ou princípio vital, corpo, morte, doença e humano. Nesse sentido,

${ }^{1}$ Remeto a trabalhos anteriores de Vanzolini (2006; 2008), nos quais tal discussão foi tratada detalhadamente. 
a autora evidencia uma "teoria indígena sobre o homem e suas relações" que é posta em operação durante o processo etiológico que atravessa o adoecimento. Sendo necessariamente resultado de agências diversas, toda doença e morte suscita a investigação do agente causador específico, algo determinante nos modos de reação ao processo que caracteriza a doença: o afastamento ou ausência da 'ang, princípio vital da vítima, de seu próprio corpo, contrapartida da atração promovida pelo agente patogênico.

A detalhada descrição dessa influência do feiticeiro sobre o 'ang e dos distintos procedimentos terapêuticos que podem ser adotados convergem para um argumento central: o corpo aweti propriamente humano é condicionado não somente pela partilha de substâncias, mas também de conhecimentos e objetos. Nesse sentido, trata-se, por um lado, de "descrever como o humano se constitui para outros humanos como parte de um mesmo corpo de substâncias, bens e conhecimentos" (p. 110); e, de outro, como o feiticeiro, desumano por quebrar as expectativas morais subjacentes à relação de parentesco mas, ao mesmo tempo, expressão de uma maldade que é também intrinsecamente humana, aparece nesse contexto.

No segundo capítulo, "Tupiat itaza porywyt: o que fazem os feiticeiros", Vanzolini, ao indagar sobre o denominador comum de todo feitiço, debruça-se de forma detalhada sobre as técnicas de feitiço, mostrando como a manipulação de objetos da feitiçaria é comparável e ao mesmo tempo oposta à construção de parentesco. As técnicas são numerosas: "atar" a vítima por meio da conjunção de seus pertences e agentes patogênicos; lançar flechinhas diretamente na vítima; confeccionar réplicas para atrair seres-fenômenos que agem com virulência sobre as vítimas; realizar certos feitiços amorosos, kuriti, utilizar roupas animais e adornos que concedem habilidades excepcionais ao feiticeiro ou oferecer comida envenenada com feitiço. Contudo, continua a autora, "o que caracteriza o feitiço é menos a técnica, e mesmo a prática do malefício, do que a ideia geral de uma intenção de causar o mal, exercendo uma influência forçada sobre a vida alheia" (p. 156). Em contrapartida, tal intencionalidade cria uma conexão corporal duradoura entre feiticeiro e enfeitiçado, condição para a realização, no caso de morte, do caro e penoso procedimento do contrafeitiço, no qual se tornará possível identificar o feiticeiro assassino e lhe infligir dores mortais através de partes do corpo da vítima.

No contexto xinguano, "toda vítima é suficientemente mesmo para que a feitiçaria seja considerada sempre abominável, mesmo quando praticada contra desconhecidos" (p. 178). Em outras palavras, todo enfeitiçado é aqui, por princípio, parente, e todo contrafeitiço e vingança se lança contra um outro, inimigo comum da comunidade. Por outro lado, como mostra Vanzolini, a identidade dos feiticeiros nunca está fora de controvérsias, que podem ocorrer entre grupos locais ou translocais. Consequentemente, as acusações, contrafeitiços e 
execuções dos feiticeiros sempre acabam sendo parcialmente ilegítimas, sintetizando uma "potência centrífuga" resultante da "desconfiança generalizada" entre próximos. Ainda assim, essas reações não prolongam simplesmente a violência do feitiço, mas podem provocar uma reflexão de que tipo de vida se deseja, conduzindo as pessoas a buscarem viver em grupo, humanamente - cessando, para tanto, o ciclo de vingança.

Em "Mo'akatu, para fazer gente", terceiro capítulo da obra, a autora descreve teorias alto-xinguanas sobre a pessoa, evidenciando como a comunhão corporal produzida entre feiticeiro e enfeitiçado é comparável àquela entre consanguíneos. Para tanto, chama atenção para o fato de que o "contínuo processo de fabricação cultural” de corpos propriamente humanos para si não é, do ponto de vista aweti, um atributo exclusivamente humano e tampouco algo "ensimesmado": sua constituição depende e resulta do processo de aquisição de potências alheias em relações intencionais com outros humanos e não humanos. O mesmo vale para o corpo do feiticeiro que, como todo corpo - mas diferentemente -, é atravessado por "múltiplas influências, fonte da sua potência, mas também de sua ruína” (p. 187).

Nesse sentido, a análise do termo mo'aká, "fazer tornar-se gente", evidencia que "todo ser precisa ser 'feito"' (p. 189) por meio de uma série de elementos, como os cuidados dos pais, a alimentação, a aplicação de remédios e pinturas corporais, o uso de adornos e rezas que moldam e embelezam o corpo. Tal processo leva à superação da fragilidade inicial da existência, à conquista de uma relativa "independência corporal" que implica uma progressiva mudança das relações às quais se está vulnerável - entre essas vulnerabilidades emergentes, o feitiço. O texto desloca-se, então, para uma descrição do conjunto de relações específicas e do processo iniciatório que levam à constituição da pessoa do xamã aweti, que passa a conviver com seres auxiliares, introjetados em seu corpo por meio de flechinhas atiradas pelo iniciador. Como argumenta Vanzolini, essa convivência é condição para a potência xamânica e está sujeita a constante negociação, análoga à das relações entre parentes, em que "a frustração das expectativas de compartilhamento tem como efeito a conversão de uma influência positiva em malefício" (p. 226).

O quarto capítulo, "Nãkywa aty: os braços fortes do feiticeiro", apresenta o processo de fabricação corporal do feiticeiro e as habilidades corporais específicas necessárias para a manipulação dos feitiços. O contraste de tal processo com o da constituição de chefes, morekwat, que implica um "tornar-se gente", revela algumas ambiguidades entre as duas figuras. Nesse sentido, os braços fortes que nomeiam o capítulo são resultado de um processo doloroso, atravessado por substâncias e objetos os quais podem remeter tanto à realização de atividades ligadas ao fortalecimento do feiticeiro quanto à pintura rituais masculinas e à fabricação de um corpo de lutador campeão, destino ideal do aspirante a chefe. 
O tênue limiar entre chefe lutador e feiticeiro, figuras que condensam em si uma mesma potência agressiva, é então evidenciado: a violência, mais do que pensável, é por vezes esperada em pontos centrais da moralidade xinguana a respeito do propriamente humano.

O capítulo seguinte, "Desfazendo parentes", explora tal moralidade e suas imbricações com a feitiçaria, propondo uma "investigação da sociologia do feitiço a partir das análises nativas de casos de enfeitiçamento" (p. 250). Trata-se, então, de investigar o modo aweti de detectar feiticeiros a partir das posições relacionais específicas ocupadas em contextos de acusação, qualificando o processo de diferenciação entre próximos imanente à feitiçaria e contrastante com a ética implícita de comensalidade e partilha entre parentes. Por vias distintas, a autora elucida uma dinâmica complexa entre processos de consanguinização e afinização ao longo do capítulo. Primeiramente, remonta às origens míticas do feitiço xinguano e, analisando certas ambiguidades da história, evidencia a indissociável ligação entre o advento do feitiço e o ciúme e inveja, ambos signos "de um conflito de perspectiva", de interesses divergentes entre pessoas próximas, e resultados "de um desejo perigoso, porque distintivo" (p. 255).

Em seguida, demonstra como categorias classificatórias que demarcam um "interior" social onde incide a feitiçaria apontam para uma concepção de aldeia aweti como grupo de parentes, cujas relações internas, contudo, nunca estão dadas a princípio. A constante reconfiguração histórica das relações de parentesco no Alto Xingu se organiza, então, em um gradiente de intensidades em função do qual variam também as expectativas morais - a forma específica de circulação e partilha de bens, palavras, substâncias - envolvidas nessas relações. Tal processo é detalhadamente apresentado tanto nas descrições de contextos, nos quais os discursos de parentesco são mobilizados para questionar, confirmar ou descartar o aparentamento e suas expectativas implícitas de compartilhamento, quanto na argumentação, de inspiração wagneriana, de que o casamento cria uma separação entre pessoas por meio da troca de pessoas. Dessa diferença instaurada entre afins, regida por rigoroso código de tratamento, podem eclodir sérias complicações de relacionamento, passando pelo desrespeito, fofocas ou acusações de feitiçaria. Assim, conclui a autora, "o feitiço diz respeito à inconsistência entre a imagem do grupo local/étnico como grupo de parentes - ou grupo de pessoas associadas pelo ideal de compartilhamento - e as diferenças internas que a todo momento aparecem impedindo a estabilização dessa unidade" (p. 300).

O último capítulo, “An tut ewaupwyka mo’aza ete: não venha desconfiar de nós (quando um dos seus estiver morrendo)", centra-se nos discursos de parentesco mobilizados em momentos polêmicos da vida em comunidade: contendas e acusações de feitiçaria em que é necessário se posicionar e acreditar em alguns em detrimento de outros, reafirmando certas relações de comunhão corporal e desejos comuns - atualizando, enfim, uma perspectiva compartilhada. A ques- 
tão rende uma interessante discussão sobre a relação aweti com o conhecimento: apontando a gradação existente entre as categorias de verdade e mentira, de modo que uma acaba por ser versão da outra de acordo com os pontos de vista particulares a partir dos quais são consideradas, a autora demonstra como a defesa de uma verdade é ao mesmo tempo efeito do parentesco e produtora deste na medida em que cria a coesão, ainda que momentânea e circunstancial, de um grupo de parentes contraposto a outros. $\mathrm{O}$ tema é especialmente evidente no modo como as redes de circulação de certas histórias coincidem com as de compartilhamento de comidas, bens e nomes que resultam da convivência, constituindo "corpos de identificação" cujos limites ganham nitidez no confronto com histórias alheias e opostas, de outras parentelas.

Em oposição às histórias, que constituem grupos de parentes, as acusações e fofocas, por sua potência disruptiva no interior de um corpo que se imaginava coletivo, são discursos que compartilham do mesmo caráter antissocial e agressivo do feitiço e precisam ser cautelosamente manipulados. Nesse sentido, o papel crucial da fofoca e sua eficácia própria são evidenciados pela descrição da autora: ainda que considerada um problema de incontinência feminina, uma incapacidade de reter no interior da casa histórias que se difundem até serem questionadas por pessoas que não compartilham de um mesmo ponto de vista, a fofoca constitui-se como canal privilegiado para acusações, visto a incerteza inerente a esses atos discursivos. Assim, um conjunto de hipóteses e especulações transformado em fofoca cristaliza um ponto de vista acusatório tentativo sem prescindir da possibilidade de revisão ou negação dessas hipóteses de acordo com as circunstâncias vividas. A eficácia da conversa de mulheres ao falar da feitiçaria está, como sugere a autora, nas respostas moderadas que suscita e no seu modo de circulação "não oficial", que evita confrontos diretos sem, contudo, jamais extingui-los. Por fim, Vanzolini aponta para o caráter antitético das analogias entre os indesejados, mas inevitáveis, processos de diferenciação engendrados pela fofoca e feitiçaria nas relações privadas e cotidianas e aqueles operantes em relações rituais intercomunitárias, nos quais a intensa variação linguística dos povos xinguanos é mobilizada para estabelecer uma forte interdependência entre eles - suas diferenças operando, portanto, como fator coesivo.

Evidentemente, a recapitulação acima, ainda que ocupe a maior parte desse texto, não dá conta da riqueza etnográfica de A flecha do ciúme, da fluidez que caracteriza seu texto, muito menos de todas as linhas argumentativas que se espraiam ao longo de seu percurso. E mesmo isso não esgotaria os recursos mobilizados por Vanzolini, que lança mão de uma série de comparações com etnografias de outros povos xinguanos e, sobretudo no "Epílogo", com outros contextos amazônicos nos quais se verificam dinâmicas análogas de "produção interna de alteridade” (p. 347). Parentesco e feitiçaria, assim como as Sol e Lua dos mitos aweti, gêmeos desiguais que atravessam de ponta a ponta essa bela monografia, engendram um movimento de contínuo desequilíbrio (cf. LÉVI-S- 
TRAUSS, 1991) na cosmopolítica aweti por meio da sempre renovada produção de inimizade num contexto etnográfico célebre por seu suposto "ethos pacifista".

\section{Agradecimentos}

O autor agradece a Dominique Gallois e a Erick Vidal pela leitura e comentários.

\section{Referências bibliográficas}

LÉVI-STRAUSS, Claude. Histoire de Lynx. Paris: Plon, 1991.

WAGNER, Roy. The Curse of Souw: principles of Daribi clan definition and alliance. Chicago: University of Chicago Press, 1967.

VANZOLINI, Marina. 2006. Centralização e faccionalismo: imagens da política no Alto Xingu. Dissertação (Mestrado em Antropologia Social) - Museu Nacional/UFRJ.

Imagens do poder: a política xinguana na etnografia. Cadernos de campo, v. 17 , n. 1, 2008, p. 89-109.

WHITEHEAD, Neil; WRIGHT, Robin. Darkness and Secrecy: the anthropology of assault sorcery and witchcraft in Amazonia. Durham/Londres: Duke University Press, 2004.

\section{autor Eduardo Santos Gonçalves Monteiro}

Graduado em Ciências Sociais pela Faculdade de Filosofia, Letras e Ciências Humanas da Universidade de São Paulo (USP). Atualmente é mestrando em Antropologia no Programa de Pós-Graduação de Antropologia Social da Universidade de São Paulo, desenvolvendo pesquisa em etnologia indígena a respeitos das redes de relações e formas políticas ameríndias entre os Timbira, grupos indígenas localizados no Maranhão e Tocantins. 